\title{
Study on Steam Huff and Puff Injection Parameters of Herringbone Well in Shallow and Thin Heavy Oil Reservoir
}

\author{
Ma Cuiyu ${ }^{1, *}$, Liu Yuetian ${ }^{1}$, Lian Peiqing ${ }^{2}$, Wang Chunhong ${ }^{1}$ and Li Jingli ${ }^{2}$ \\ ${ }^{1}$ Department of Petroleum Engineering, China University of Petroleum (Beijing), Beijing 102249, China; ${ }^{2}$ Sinopec \\ Petroleum Exploration \& Development Research Institute, Beijing 100083, China
}

\begin{abstract}
With the development of heavy oil recovery technology, the application of herringbone well in heavy oil exploitation gradually expands. In this paper, the development effect of herringbone well is compared with that of horizontal well in shallow and thin heavy oil reservoir. The results show that herringbone well could receive an anticipated development effect and economic benefit in steam huff and puff. Numerical simulation and gray relational analysis are used to study the sensitivity of injection parameters during steam huff and puff of herringbone well in shallow and thin heavy oil reservoir. The descending order of the sensitivity injection parameters during steam huff and puff of herringbone well is concluded. Cycle steam injection volume is the most important parameter which affects the productivity of herringbone well, and the sequence of other parameters is steam dryness, steam injection rate and soak time. As a result, the steam injection parameters are optimized. Optimization results are as follows: cycle steam injection volume is 7000 t, steam dryness is greater than $50 \%$, steam injection rate is $600 \mathrm{t} / \mathrm{d}$, and soak time is 4 to 7 days.
\end{abstract}

Keywords: Steam stimulation, sensitivity analysis, numerical simulation, gray relational analysis, shallow and thin heavy oil reservoir.

\section{INTRODUCTION}

With the development of drilling and production technology, the application of herringbone well in oil exploitation gradually expands [1-3]. Compared with horizontal well [46], herringbone well gets more contact area with reservoir, therefore, the application of herringbone well in heavy oil reservoir can greatly improve single well productivity. Herringbone well production can significantly increase injection volume, expand steam swept volume and improve steam utilization ratio, which will help to improve and enhance the development efficiency [7-9].

The development practice shows that geologic parameters and steam injection parameters are the main factors that influence the effect of steam huff and puff [10-13]. In this paper, we take $\mathrm{X}$ reservoir as an example, assume that the geologic parameters are fixed, and study how to develop the heavy oil reservoirs in shallow and thin layers effectively. The influence of injection parameters (steam dryness, steam injection rate, cycle steam injection volume and soak time) on steam huff and puff of herringbone well is studied, and the optimal values of injection parameters are calculated.

\section{RESERVOIR GENERALIZATION}

$\mathrm{X}$ reservoir is a shallow and thin heavy oil reservoir. According to the in-situ data from oil field, oil layers generally retain between aquifers and mudstone layers, and distribute discretely. The depth of $\mathrm{X}$ reservoir is about 200 to 500

*Address correspondence to this author at the Department of Petroleum Engineering, China University of Petroleum-Beijing, 18 Fuxue Road, Changping, Beijing, 102249 China;

E-mail: macuiyu25@sina.com meters, and the oil-bearing series of each block is different and relatively homogeneous.

In order to compare the influence of steam dryness, steam injection rate, cycle steam injection volume, and soak time on steam huff and puff, as shown in (Fig. 1), a typical geological model is built based on the characteristics of $\mathrm{X}$ reservoir. The average physical parameters of the reservoir are applied in geological model, and the main parameters of the model are shown in (Table 1). CMG software is applied to simulate steam huff and puff, grid dimension is $61 \times 31 \times 5$, grid step is $10 \mathrm{~m} \times 10 \mathrm{~m}$, and plane and vertical of reservoir are homogeneous.

\section{DEVELOPMENT EFFECTS OF DIFFERENT WELL-TYPE STEAM HUFF AND PUFF}

The main wellbore of horizontal well is $400 \mathrm{~m}$; the main wellbore of herringbone well is $400 \mathrm{~m}$, the branch number is four, the branch angle is $25^{\circ}$, and the branch length is $100 \mathrm{~m}$.

In the steam huff and puff process, cycle steam injection volume is $5000 \mathrm{t}$, steam dryness is 0.5 , and steam temperature is $300^{\circ} \mathrm{C}$. The largest liquid producing capacity of well is $120 \mathrm{~m}^{3} / \mathrm{d}$, and the soak time is 5 days.

In order to compare two kinds of well-type development effect further, the flow field distributions of different welltype steam huff and puff are shown as follows, including distribution of temperature, oil viscosity, and oil saturation.

The distributions of reservoir temperature and oil viscosity are shown in (Fig. 2 and Fig. 3). As we can see from the figures, the improving range of temperature and the reducing range of oil viscosity around the herringbone well are bigger than that around horizontal well, which significantly improve 


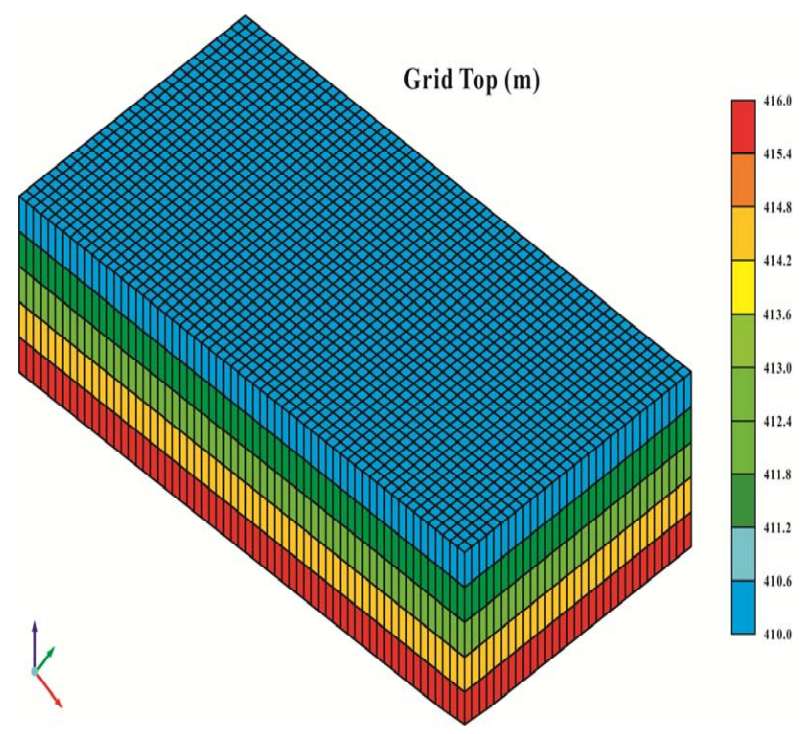

Fig. (1). Typical geological model.

Table 1. The Parameters of Typical Geological Model

\begin{tabular}{|c|c|}
\hline Parameter & Value \\
\hline Reservoir depth, m & 410 \\
\hline Effective thickness, $\mathrm{m}$ & 6 \\
\hline NTG & 0.8 \\
\hline Plane permeability, $\mathrm{mD}$ & 1736 \\
\hline Porosity & 0.35 \\
\hline $\mathrm{S}_{\mathrm{oi}}$ & 0.68 \\
\hline Original reservoir pressure, $\mathrm{MPa}$ & 4.1 \\
\hline Original reservoir temperature, ${ }^{\circ} \mathrm{C}$ & 19 \\
\hline Degassed oil viscosity $\left(19^{\circ} \mathrm{C}\right), \mathrm{mPa} \cdot \mathrm{s}$ & 4932 \\
\hline $\begin{array}{l}\text { Thermal conductivity of rock skeleton, } \\
\qquad \mathrm{KJ} /\left(\mathrm{m} \cdot \mathrm{d} \cdot{ }^{\circ} \mathrm{C}\right)\end{array}$ & 96.4 \\
\hline Rock heat capacity, $\mathrm{KJ} /\left(\mathrm{m}^{3} \cdot{ }^{\circ} \mathrm{C}\right)$ & 2400 \\
\hline
\end{tabular}
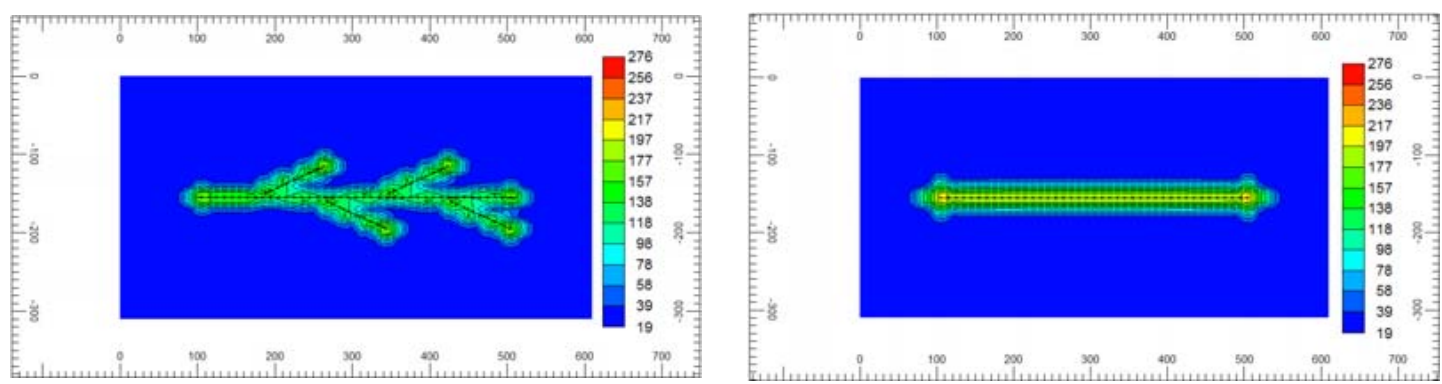

(a) Distribution of temperature after soaking in cycle 1
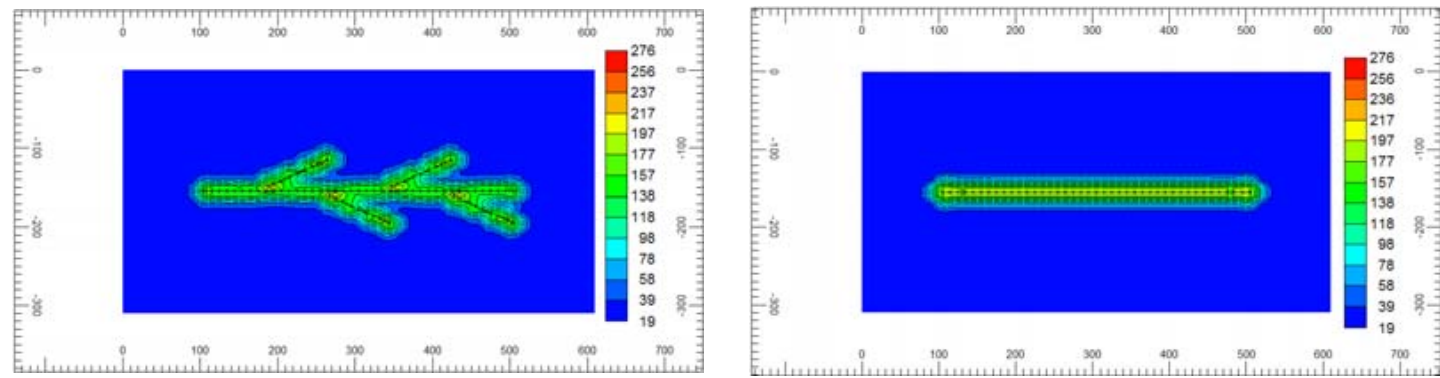

(b) Distribution of temperature after soaking in cycle 4

Fig. (2). Comparison of temperature distribution.

the producing reserves, and finally improve reservoir development effect.

As shown in (Fig. 4), in the production process, the oil saturation around horizontal well and herringbone well falls, and the reducing range of oil viscosity around the herringbone well is bigger. According to the development effect, herringbone well is better, so the efficient development well type of shallow and thin heavy oil reservoir is herringbone well.

Fig. (5) shows development effect of steam huff and puff between horizontal well and herringbone well. As we can see from the figure, the development effect of herringbone well is better than horizontal well. It is mainly due to the bigger contact area between herringbone well and the reservoir, which increases steam swept volume, reservoir heating area, oil viscosity reduction area, and oil movable area.

\section{GRAY RELATIONAL ANALYSIS ON INJECTION PARAMETERS ABOUT STEAM HUFF AND PUFF OF HERRINGBONE WELL}

Numerical simulation and gray relational analysis $[14,15]$ are used to study the sensitivity of injection parameters 

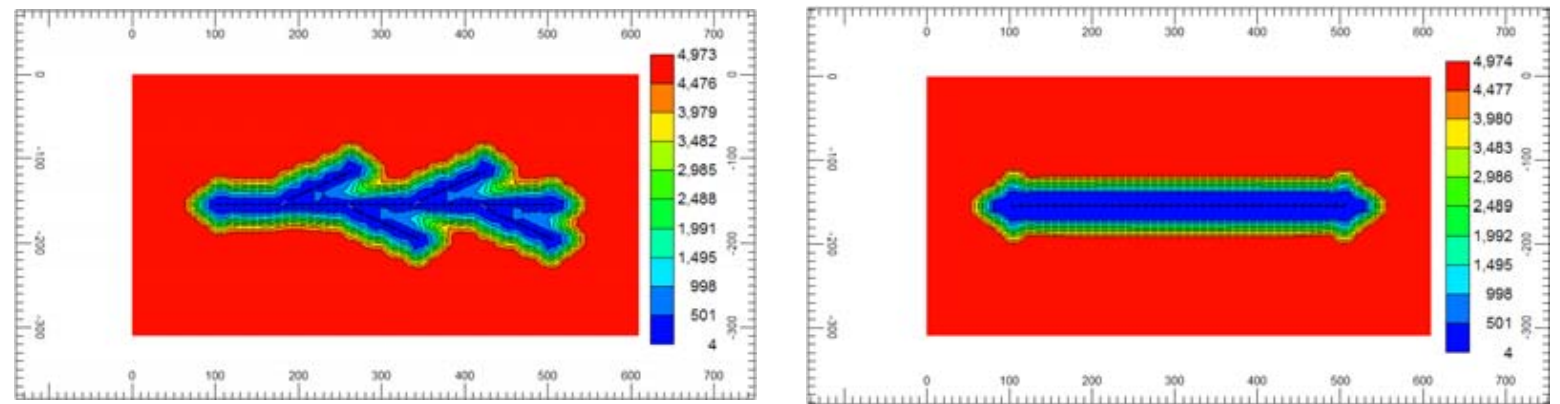

(a) Distribution of oil viscosity after soaking in cycle 1
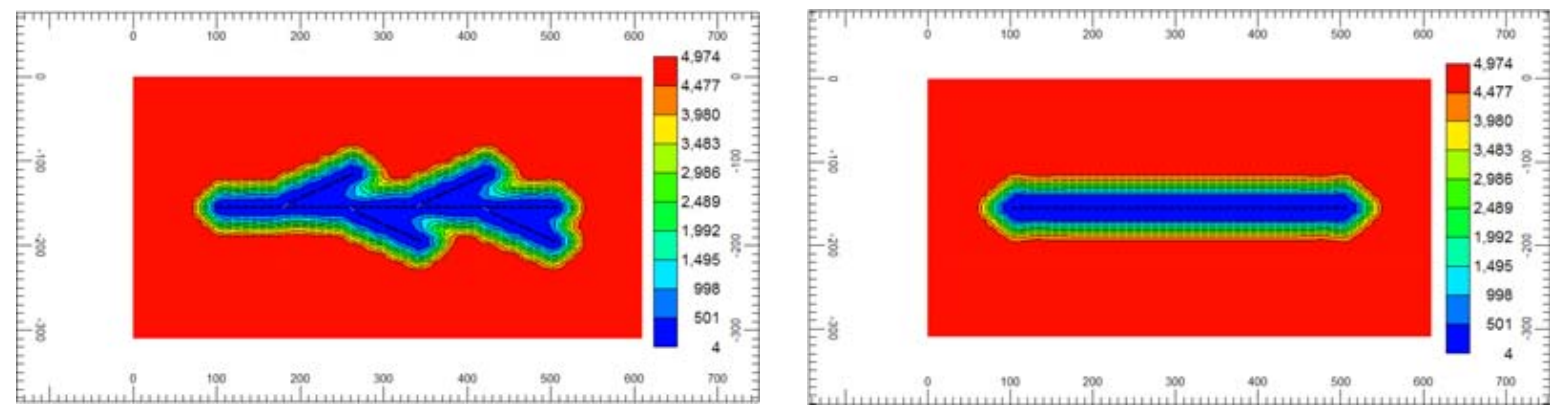

(b) Distribution of oil viscosity after soaking in cycle 4

Fig. (3). Comparison of oil viscosity distribution.

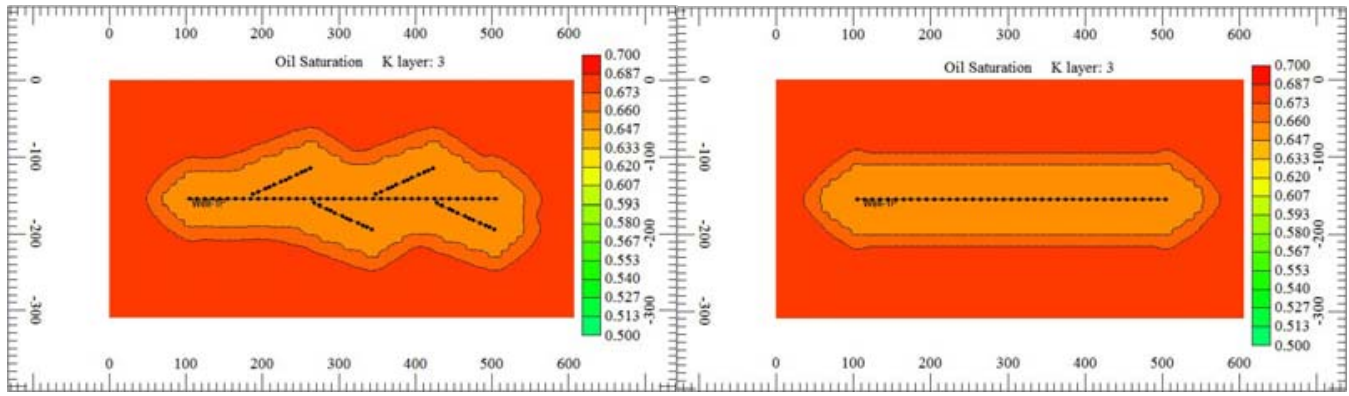

(a) Distribution of oil saturation after cycle 1

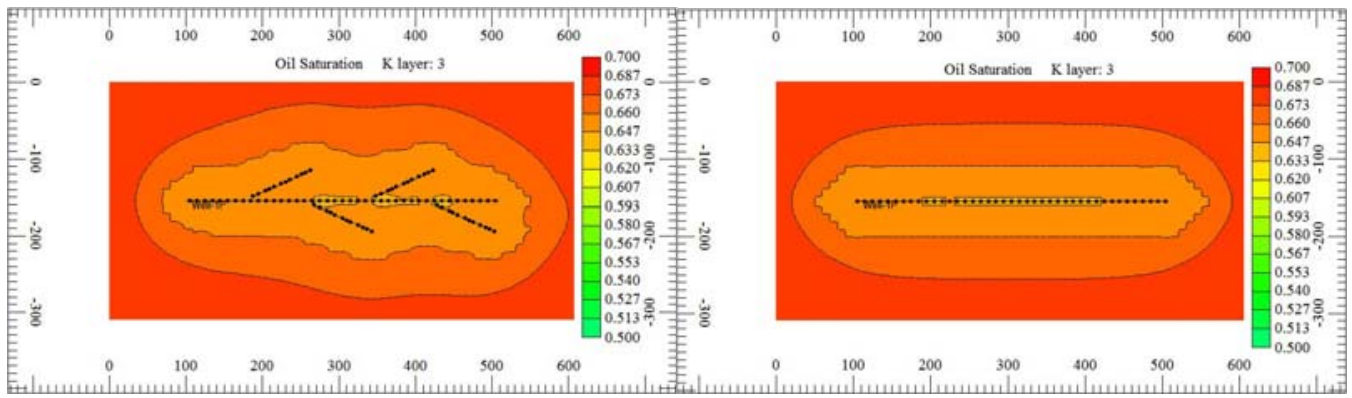

(b) Distribution of oil saturation after cycle 4

Fig. (4). Comparison of oil saturation distribution.

in steam huff and puff. Steam injection parameters include cycle steam injection volume, steam dryness, steam injection rate and soak time.

As shown in (Table 2), cycle steam injection volume, steam dryness, steam injection rate and soak time are changed respectively and proportionally, then the development effects of steam huff and puff are compared.
Gray relational analysis is used to compare the degree of correlation between sequence and reference sequence by judging the degree of geometry similarity of each sequence curve. The closer the geometry of curve is, the greater the degree of association between sequence and reference sequence. It is used to quantitatively describe and compare the development and changes of a system. 


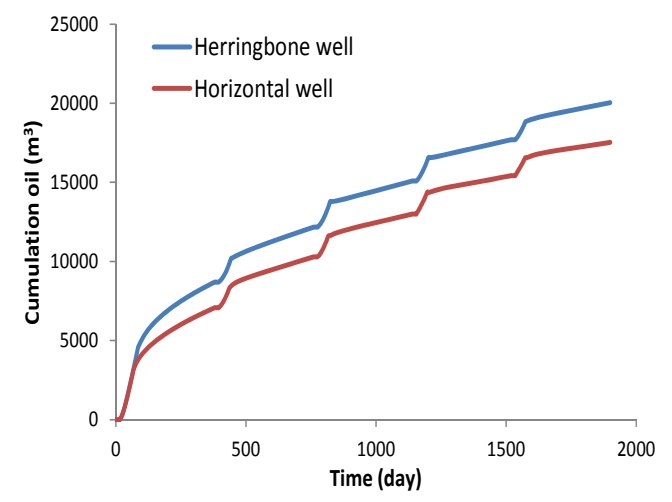

Fig. (5). Development effect of steam huff and puff both horizontal well and herringbone well.

(1)Analytical sequence determination

Selected cycle oil production of herringbone well as the reference sequence, written as follows:

$$
X_{0}=\left\{X_{0}(k) \mid k=1,2, \cdots, n\right\}
$$
data.

Where $\mathrm{n}$ is the length of the sequence, i.e., the number of

In steam injection parameters sensitivity analysis, cycle steam injection volume, steam dryness, steam injection rate and soak time are selected as comparative sequence. It is written as follow:

$$
X_{i}=\left\{X_{i}(k) \mid k=1,2, \cdots, n\right\} \quad(i=1,2, \cdots, m)
$$

Where $\mathrm{m}$ is the number of factors.

(2) Variables dimensionless

In order to make the variables dimensionless, the following formula is used:

$$
X_{i j}^{\prime}=\frac{X_{i j}-X_{j \min }}{X_{j \max }-X_{j \min }} \quad i=1,2, \cdots, n ; j=1,2, \cdots, m
$$

\section{(3) Correlation coefficient calculation}

According to the dimensionless data sequence matrix, absolute difference value and extreme value between each factor sequence and observed value of reference sequence

\begin{tabular}{|c|c|c|c|c|}
\hline Cycle steam injection volume (t) & Team injection rate $(t / d)$ & Steam dryness $(\%)$ & Soak time (d) & Cycle oil production (t) \\
\hline 2000 & 500 & 50 & 5 & 7393 \\
\hline 3500 & 500 & 50 & 5 & 8077 \\
\hline 5000 & 500 & 50 & 5 & 8696 \\
\hline 6500 & 500 & 50 & 5 & 9311 \\
\hline 8000 & 500 & 50 & 5 & 9849 \\
\hline 5000 & 200 & 50 & 5 & 8573 \\
\hline 5000 & 350 & 50 & 5 & 8687 \\
\hline 5000 & 500 & 50 & 5 & 8696 \\
\hline 5000 & 650 & 50 & 5 & 8726 \\
\hline 5000 & 800 & 50 & 5 & 8730 \\
\hline 5000 & 500 & 20 & 5 & 8297 \\
\hline 5000 & 500 & 35 & 5 & 8530 \\
\hline 5000 & 500 & 50 & 5 & 8696 \\
\hline 5000 & 500 & 65 & 5 & 8915 \\
\hline 5000 & 500 & 80 & 5 & 9144 \\
\hline 5000 & 500 & 50 & 2 & 8680 \\
\hline 5000 & 500 & 50 & 3.5 & 8690 \\
\hline 5000 & 500 & 50 & 5 & 8696 \\
\hline 5000 & 500 & 50 & 6.5 & 8725 \\
\hline 5000 & 500 & 50 & 8 & 8724 \\
\hline
\end{tabular}
can be received:

Table 2. Cycle Oil Production Under Different Steam Injection Parameters 


$$
\begin{aligned}
& \Delta_{i}(k)=\left|x_{0}^{\prime}(k)-x_{i}^{\prime}(k)\right| \\
& \Delta_{\max }=\max _{k=1}^{n} \max _{i=1}^{m}\left|x_{0}^{\prime}(k)-x_{i}^{\prime}(k)\right| \\
& \Delta_{\min }=\min _{k=1}^{n} \min _{i=1}^{m}\left|x_{0}^{\prime}(k)-x_{i}^{\prime}(k)\right|
\end{aligned}
$$

The correlation coefficient at a point between reference sequence and compared sequence is:

$$
\xi_{i}(k)=\frac{\Delta_{\min }+\rho \Delta_{\max }}{\Delta_{i}(k)+\rho \Delta_{\max }}
$$

Where $\rho$ is resolution ratio with value range 0 to 1 . The value of $\rho$ influences the value of the correlation coefficient. The smaller $\rho$ is, the greater the resolution. This paper takes $\rho$ as 0.5 . The correlation coefficient at each observation time between reference sequence and compared sequence can be received through formula (7).

(4) Correlation calculation

$$
\gamma_{i}=\frac{1}{n} \sum_{k=1}^{n} \xi_{i}(k) i=1,2, \cdots, m ; k=1,2, \cdots, n
$$

The correlation degree between the sequence of cycle oil production and each factors can be received through formula (8), and the results are shown in (Table 3). Table (3) shows the sensitivity of injection parameters during steam huff and puff of herringbone well in shallow and thin heavy oil reservoir. Thus, the sensitivity descending order of injection parameters is as follow: cycle steam injection volume $>$ steam dryness $>$ steam injection rate $>$ soak time.

\section{STEAM INJECTION PARAMETERS OPTIMIZA- TION DURING STEAM HUFF AND PUFF OF HER- RINGBONE WELL}

Based on the analysis of the injection parameter sensitivity during steam huff and puff of herringbone well, steam injection parameters are optimized.

\subsection{Cycle Steam Injection Volume Optimization}

According to the development experience of heavy oil thermal recovery, cycle steam injection volume directly affects the effects of steam huff and puff. Within a certain range, cycle oil production and cycle steam injection volume are proportional. For specific heavy oil reservoir, steam injection volume has an optimal range. If steam injection volume is too small, the cycle oil production is low. The larger the steam injection volume is, the greater the heating range. Therefore, oil production will increase. However, if the steam injection volume is too large, it will cause oil to be pushed away from the bottom of well, oil-steam ratio drops and production downtime also increases accordingly.

In the certain steam injection rate, steam dryness and soak time, the production condition of steam huff and puff simulation under different cycle steam injection volume is shown in (Fig. 6 and Fig. 7).

Fig. (6) and Fig. (7) show that with the increase of cycle steam injection volume, cumulative oil production increases and oil-steam ratio reduces. When cycle steam injection volume increases to more than 7000 t, increment of cumulative oil production reduces. Therefore, the preferred value of cycle steam injection volume is $7000 t$.

\subsection{Steam Dryness Optimization}

Numerical simulation, physical simulation and oilfield actual production show that steam dryness is an important factor which influences huff and puff development effects. Under the same cycle steam injection volume and steam injection rate, the higher the steam dryness is, the more the cycle oil production. Because the greater the heat enthalpy value the steam carries, the larger the heating radius is.

Based on the optimized cycle steam injection volume of $7000 t$, steam dryness is optimized. Respectively setting different steam dryness, the simulation results are shown in (Fig. 8).

Fig. (8) shows that with the increase of steam dryness, cumulative oil production and oil-steam ratio increase. However, higher steam dryness requires higher steam injection rate and better insulation oil tube, which means higher inputs. Therefore, for $\mathrm{X}$ reservoir, it can achieve a great huff and puff production effect as long as steam dryness is greater than $50 \%$.

\subsection{Steam Injection Rate Optimization}

Based on the optimized cycle steam injection volume of $7000 \mathrm{t}$ and steam dryness fraction of $50 \%$, steam injection rate is optimized. Respectively setting different steam injection rate, the simulation results are shown in (Table 4).

Steam injection rate depends mainly on reservoir thickness, oil viscosity, reservoir pressure, injection pressure and steam absorption capacity of reservoir. Under the same steam injection volume, if the steam injection rate is too low, wellbore heat loss will increase and bottom-hole steam dryness will reduce; as a result, it will reduce the effect of steam huff and puff. However, if the steam injection rate is too high, reservoir will be fractured and injection steam will flow away from well. This will lead to the result that the formation near well is not effectively heated and the utilization of steam also is reduced. Therefore, the steam injection

Table 3. Correlation Degrees of Steam Stimulation Parameters and Cycle Oil Production

\begin{tabular}{|c|c|c|c|}
\hline Affecting factor & Cycle steam injection volume & Steam injection rate & Steam dryness \\
\hline \hline Correlation degree & 0.863 & 0.669 & 0.725 \\
\hline Correlation order & 1 & 3 & 2 \\
\hline
\end{tabular}


pressure of numerical simulation should not be higher than the formation fracture pressure.

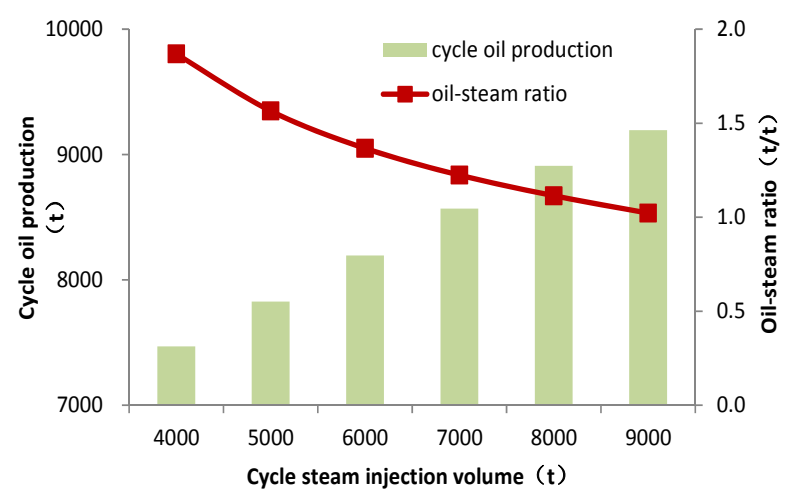

Fig. (6). The relationship of cumulative oil production \& oil-steam ratio with cycle steam injection volume.

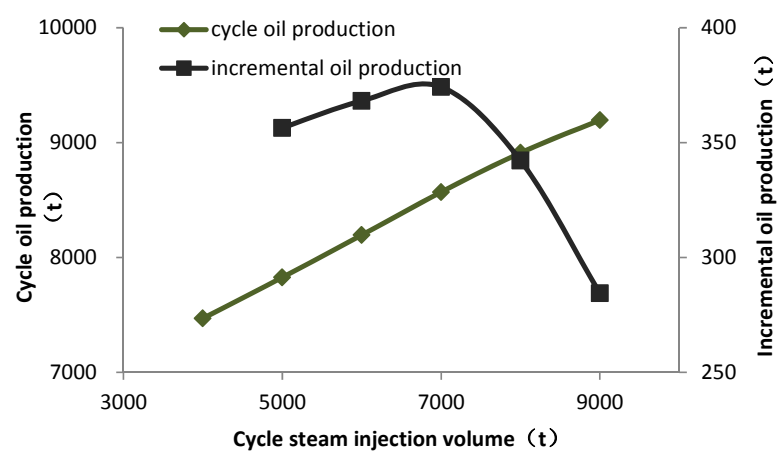

Fig. (7). The relationship of cumulative oil production \& incremental oil production with cycle steam injection volume.

As shown in (Table 4), with the increase of steam injection rate, cumulative oil production increases. However, when steam injection rate increases to more than $600 \mathrm{t} / \mathrm{d}$, cumulative oil production reaches its maximum. Therefore, the preferred value of steam injection rate is $600 \mathrm{t} / \mathrm{d}$. As shown in (Table 4), steam injection rate has little effect on cumulative oil production. The main reason is that formation is shallow and heat loss in the tubing is very small.

\subsection{Soak Time Optimization}

In order to effectively carry the steam heat to reservoir, make the reservoir fully heated and improve the utilization of steam, soak is needed after steam injection. However, soak time cannot be too long, otherwise, that will increase the heat loss to top and bottom layers.

Based on the optimized cycle steam injection volume of $7000 \mathrm{t}$, steam dryness of $50 \%$, and steam injection rate of $600 \mathrm{t} / \mathrm{d}$, soak time is optimized. Respectively setting different soak time, the simulation results are shown in (Table 5).

As shown in Table 5, with the increase of soak time, bottom-hole temperature significantly reduces and cumulative oil production first increases, then decreases. Because the effect of soak time on cumulative oil production is relatively minor, the preferred soak time is $4 \sim 7$ days for maintaining higher bottom-hole temperature and shorter production downtime.

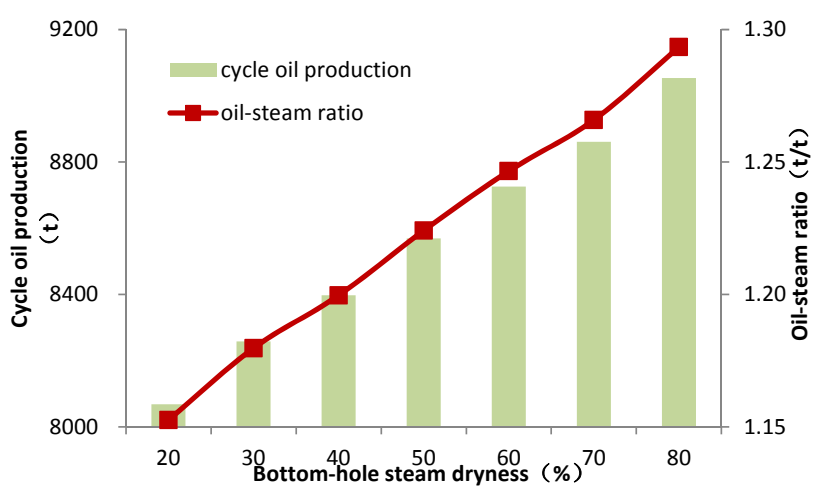

Fig. (8). The relationship of cumulative oil production \& oil-steam ratio with steam dryness.

\section{CONCLUSIONS}

(1) Based on the model built on the typical geological characteristics of the block, the development effects of herringbone well and horizontal well are compared and analyzed. The results show that the rational well-type which could receive an anticipated development effect and economic benefit in steam huff and puff is herringbone well.

(2) The sensitivity descending order of injection parameters during steam huff and puff in shallow and thin heavy oil reservoir is as follow: cycle steam injection volume, steam dryness, steam injection rate, and soak time.

(3) Cycle steam injection volume is the primary production parameter influencing huff and puff development, and

Table 4. Cycle Production Effects Under Different Steam Injection Rate

\begin{tabular}{|c|c|c|c|}
\hline Steam injection rate (t/d) & Cumulative oil production (t) & Oil-steam ratio (t/t) & Cumulative steam injection (t) \\
\hline \hline 300 & 7992 & 1.14 & 7000 \\
\hline 400 & 8362 & 1.19 & 7000 \\
\hline 500 & 8550 & 1.22 & 7000 \\
\hline 600 & 8701 & 1.24 & 7000 \\
\hline 700 & 8661 & 1.24 & 7000 \\
\hline
\end{tabular}


Table 5. Cycle Production Effects Under Different Soak Time

\begin{tabular}{|c|c|c|c|c|}
\hline Soak time (d) & Cumulative oil production (t) & Oil-steam ratio (t/t) & Cumulative steam injection (t) & Bottom-hole temperature $\left({ }^{\circ} \mathbf{C}\right)$ \\
\hline \hline 3 & 8359 & 1.19 & 7000 & 209 \\
\hline 4 & 8685 & 1.24 & 7000 & 196 \\
\hline 5 & 8701 & 1.24 & 7000 & 192 \\
\hline 6 & 8712 & 1.24 & 7000 & 181 \\
\hline 7 & 8740 & 1.25 & 7000 & 172 \\
\hline 8 & 8737 & 1.25 & 7000 & \\
\hline
\end{tabular}

the preferred value of cycle steam injection volume is 7000t. The higher the steam dryness is, the better the effect of production.

(4) In the process of steam huff and puff in shallow and thin heavy oil reservoir, steam injection rate is a relatively insensitive parameter. To improve the utilization of steam and shorten the production downtime, the preferred soak time is $4 \sim 7$ days.

\section{CONFLICT OF INTEREST}

The author(s) confirm that this article content has no conflicts of interest.

\section{ACKNOWLEDGEMENT}

The authors are grateful for the financial support by National Science and Technology Key Project "Complex oil \& gas geology and EOR Technology" (No. 2011ZX05009).

\section{REFERENCES}

[1] D.K. Triolo, and R.A. Mathes, "Review of a Multi-Lateral Drilling and Stimulation Program". Paper No. SPE 39242, In: SPE/IADC Middle East Drilling Technology Conference, Bahrain, 23-25 November, 1997.

[2] Y.C. Geng, and M.X. Sun, "Drilling technology of fishbone horizontal multilateral well in shengli oilfield", Oil Drilling \& Production Technology, vol. 29, no. 5, pp. 20-22, 2007.

[3] J. Lin, X. Wang, and Z.H. Song, "Herringbone multilateral wells drilling technology for shallow heavy oil reservoirs in xinjiang oilfield", Petroleum Drilling Techniques, vol. 35, no. 2, pp. 11-14, 2007.

[4] J.F. Sun, Z.Q. Li, and G.H. Wu, "Advancement and Application of Thermal Recovery Technology in Heavy Oil Reservoir in Shengli Petroleum Province". Paper No. SPE 14582, In: International Petroleum Technology Conference, Bangkok, Thailand, 7-9 February, 2012.

[5] G. Li, G.J. Moridis, and K.N. Zhang, The Use of Huff and Puff Method in a Single Horizontal Well in Gas Production from Marine Gas Hydrate Deposits in the Shenhu Area of the South China Sea.
Paper No. SPE 131160, In: International Oil and Gas Conference and Exhibition in China, Beijing, China, 8-10 June, 2010.

[6] Y.Q. Yao, X.C. Yuan, and G.Q. Qiu, "Thermal recovery of a thinbeded reservoir by horizontal wells in le'an heavy oilfield", Acta Petrolei Sinica, vol. 16, no. 3, pp. 48-51, 1995.

[7] L.C. Leung, "Numerical evaluation of the effect of simultaneous steam and $\mathrm{CO}_{2}$ injection on the recovery of heavy oil", Journal of Petroleum Technology, vol. 35, no. 9, pp. 1591-1599, 1983 .

[8] D.W. Boardman, and S.A. Intevep, "Designing the Optimal MultiLateral Well Type for a Heavy Oil Reservoir in Lake Maracaibo, Venezuela". Paper No. SPE 37554. In: International Thermal Operations and Heavy Oil Symposium, Bakersfield, California, 10-12 February, 1997.

[9] J.Z. Liang, W.L. Guan, B.J. Wang, and Y. Wu, "Feasibility Study of In-Situ Combustion Huff and Puff for EOR in Super-Deep Heavy Oil Reservoir". Paper No. IPTC 16408. In: 6th International Petroleum Technology Conference, Mar 26 - 28, 2013, Beijing, China, 2013

[10] Z. Mendez, J.M. Alvarez, E.C. Escobar, C.E. Peter, and Intevep S.A. "Cyclic steam injection with additives: laboratory and field test results of steam/foam and steam/solvent processes". Paper No. SPE 24632 In: SPE Annual Technical Conference and Exhibition, 4-7 October 1992, Washington, D.C. USA.

[11] M. Kamil, A. TatNIPIneft, and I. Nail, "The optimization of the gas-steam injection using numerical simulation". Paper No. SPE 105199. In: SPE Middle East Oil and Gas Show and Conference, Kingdom of Bahrain, 11-14 March, 2007.

[12] C.R.K. Murty, K. Kumar, A. Bapco, J-H. de Galard, and V. Mazeraud, "Thermal EOR Pilot Plan for a Shallow Limestone Reservoir (Rubble Zone) in Bahrain Field". Paper No. SPE 120569. In: SPE Middle East Oil and Gas Show and Conference, 15-18 March, 2009, Bahrain.

[13] G.F. Wang, D.Y. Jiang, and H.J. Zhao, "Thermal Recovery Technology Research and Application of Thin Heavy Oil Reservoir". Paper No. SPE 131527. In: International Oil and Gas Conference and Exhibition in China, Beijing, China, 8-10 June, 2010.

[14] X.H. Wu, A.Z. Xu, and H.L. Fan, "An integrated evaluation on factors affecting the performance of superheated steam huff and puff in heavy oil reservoirs", Petroleum Exploration and Development, vol. 37, no. 5, pp. 608-613, 2010.

[15] X.H. Wu, B.J. Dong, A.Z. Xu, Z. Fan, and R. Wang, "Superheated Steam Huff and Puff to Revivify a Marginal Pre-salt Heavy Oil Reservoir". Paper No. SPE 134082. In: SPE Asia Pacific Oil and Gas Conference and Exhibition, 18-20 October 2010, Brisbane, Queensland, Australia.

(C) Cuiyu et al.; Licensee Bentham Open.

This is an open access article licensed under the terms of the Creative Commons Attribution Non-Commercial License (http://creativecommons.org/licenses/by-nc/3.0/) which permits unrestricted, non-commercial use, distribution and reproduction in any medium, provided the work is properly cited. 